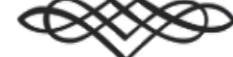

Suarez's reply to the condemnation of Defensio fidei by the

Paris Parliament. Latin text, translation and critical annotation

\title{
La réplica de Suárez a la condena de la Defensio fidei por el Parlamento de París. Texto latino, traducción y anotación critica
}

Leopoldo José Prieto López

Universidad Francisco de Vitoria (UFV)

leopoldojose.prieto@ufv.es

DOI: https://doi.org/10.15366/bp.2020.24.006

Bajo Palabra. II Época. № 24. Pgs: 107-134

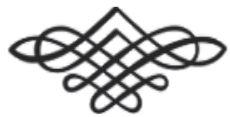


Recibido: 02/02/2020

Aprobado: 28/07/2020

\section{Resumen}

El artículo presenta el texto latino y una traducción de la réplica de Francisco Suárez de la condena de la Defensio fidei por el Parlamento de París ocurrida en 1614, así como la censura teológica del cardenal Belarmino del decreto parisiense de condena. Junto a una justificación inicial de la necesidad de un trabajo de esta índole trabajo, el artículo expone unas valoraciones conclusivas sobre las cuestiones fundamentales que ocasionaron la condena parisiense de la Defensio fidei: las doctrinas de la potestad política indirecta del Papa y del tiranicidio.

Palabras clave: Condena parisina de la Defensio fidei, potestad politica indirecta del Papa, tiranicidio,

\section{Abstract}

The article presents the latin text and a translation of Francisco Suárez's reply to the condemnation of Defensio fidei by the Paris Parliament in 1614, as well as the Cardinal Belarmino's theological censure of the Parisian decree of condemnation. Together with an initial justification of the need for such a work, the article concludes with some assessments of the fundamental topics that caused the Defensio fideis parisian condemnation: the doctrines of the Pope's indirect political power and of the tyrannicide.
Keywords: Defensio fideis parisian condemnation, Pope's indirect political power, tyrannicide. 


\section{Naturaleza y justificación de este trabajo}

En i6i9, dos años después de la muerte de Sú́rez, comenzaba el jesuita Baltasar Álvares el trabajo de publicación de las obras póstumas de Suárez. El plano de trabajo aparecía esbozado por Álvares en el prefacio Ad lectorem del primer tomo del tratado suareciano De Gratia Dei. En dicho plano se incluía un volumen misceláneo al que Álvares se refería como "una obra que contiene acumulados diversos consejos" (opus variis aggestum consiliis) y al que algo más adelante llama igualmente "consejos y cuestiones" (consilia et quaestiones) ${ }^{1}$. Según Joaquim de Carvalho, este volumen misceláneo era "una obra menor, integrada por la colección de opiniones de Suárez sobre una serie de consultas, que servía para testimoniar el prestigio de Suárez y la aplicación de su talento y saber a la dilucidación de algunos casos concretos, susceptibles de controversia cuando no ya objeto de litigio" 2 .

Por razones que desconocemos, mientras que las demás obras póstumas de Suárez salieron a la luz poco a poco, el proyecto de Álvares de publicación de este opus variis aggestum consiliis no llegó a puerto. Solo con la publicación de los dos tomos de la obra titulada Conselhos e pareceres (entre 1948 y 1952) por parte de la Universidad de Coimbra ha quedado paliado, al menos en parte, el malogrado proyecto de Álvares. Estos Conselhos e pareceres de Francisco Suárez contienen una miscelánea de escritos de Suárez conservados en el Archivo y en la Biblioteca general de la Universidad de Coimbra. En dichos tomos se recogen piezas del primer cuarto del siglo XVII, así como algunas copias de originales realizadas en el siglo XVIII. El primer tomo recibió el título de Consilia moralia R. P. Doctoris Francisci Suares. El segundo, a su vez, llevaba el título de Consilia sive opuscula moralia R. P. Doctoris Francisci Suares.

El contenido de estos Conselhos e pareceres está formado en general por breves escritos de ocasión correspondientes a la actividad desplegada por Suárez en sus

\footnotetext{
* Este trabajo es resultado del Proyecto "Sociedad, política y economía: Proyecciones de la Escolástica española en el pensamiento británico y anglosajón” (Programa Estatal de Fomento de la Investigación Científica y Técnica de Excelencia, referencia: FFI2017-84435-P), financiado por la Agencia Espańola de Investigación (AEI) y el Fondo Europeo de Desarrollo Regional (FEDER), del que el autor es el IP primero.

${ }^{1}$ Cf. Suárez, F., Tractatus de Gratia Dei seu de Deo Salvatore, justificatore et liberi arbitrii adjutore per gratiam suam, en R. P. Francisci Suarez e Societate Jesu opera omnia, vol. VII, Parisiis, apud L. Vivès, 1857, p. V.

2 Carvalho, J. de, "Nota preliminar" de Suárez, F., Conselhos e pareceres, tomo I, Acta Universitatis Conimbrigensis, Coimbra, Atlántida, 1948, p. V. Traducción propia.
} 
últimos años como teólogo consultor. Entre ellos hay soluciones de casos diversos, informes, respuestas a cuestiones sobre materias de teología dogmática, moral, liturgia, derecho canónico, etc.

En el tomo II de los Conselhos e pareceres se encuentra un escrito de Suárez relacionado con la intensa polémica internacional ocasionada por la publicación en Coimbra, en 1613, de la Defensio fidei. Se trata, en efecto, de un breve texto, escrito en latín cuyo título reza Acta et decreta in Parlamento parisiensi contra librum de fidei defensione Francisci Suarez damnabilem continere doctrinam contra religionem catholicam, ideoque digna esse, ut per Ecclesiam damnentur, et prohibeantur, ex eisdem actis his modis ostenditur ${ }^{3}$. Estos Acta et decreta fueron incluidos años más tarde, en 1979, en un volumen del Corpus hispanorum de pace, del CSIC, preparado por Luciano Pereña y sus colaboradores, titulado Francisco Suárez, De iuramento fidelitatis. Estudio preliminar ${ }^{4}$. Hay que decir que los editores de aquel volumen omitieron indicar la procedencia de estos Acta et decreta, que probablemente no era sino el tomo II de los Conselhos e pareceres, publicado en Coimbra veintisiete años atrás.

Sin embargo, en este mismo volumen del CSIC, en las páginas inmediatamente anteriores a los Acta et decreta, se incluía otro documento, escrito en español y titulado Indicios y pruebas de que el proceso y decreto del Parlamento de París contra el libro de la fe del Padre Francisco Suárez contiene doctrina perniciosa y escandalosa en la fe, y por tanto ser todo aquel escrito digno de ser reprobado y prohibido en la Iglesia, lo qual se prueba del mismo processo 5 . De estos Indicios y pruebas, escritos en español, Pereña y sus colaboradores indicaban como origen el ms. 243, fol. 351 de la Colleç̧áo Pombalina de la Biblioteca Nacional de Lisboa. Nosotros, por nuestra parte, hemos encontrado también este texto suareciano en el Fondo Bibliográfico Antiguo de la Universidad de Granada ${ }^{6}$, que ha digitalizado el documento, poniéndolo a disposición de la investigación científica.

\footnotetext{
3 Suárez, F., Conselhos e pareceres, tomo II, vol. II, Acta Universitatis Conimbrigensis, Atlántida, Coimbra 1952, pp. 217-221

4 Suárez, F., "Acta et decreta in parlamento parisiensi contra librum de fidei defensione Francisci Suarez", en Pereña, L. et alii (eds.), Francisco Suárez, De iuramento fidelitatis. Estudio preliminar. Conciencia y politica, Madrid, CSIC, 1979, pp. 597-602

5 Suárez, F., "Indicios y pruebas de las actas y decretos del Parlamento de París contra el libro de sobre la defensa de la fe de Francisco Suárez", Ibid., pp. 592-596

${ }^{6}$ Suárez, F., "Indicios y pruebas de las actas y decretos del Parlamento de París contra el libro de sobre la defensa de la fe de Francisco Suárez", en Fondo Bibliográfico Antiguo de la Universidad de Granada, https://digibug. ugr.es/handle/10481/17289
} 
Ambos textos, a pesar de la diferencia en los títulos y en la lengua de redacción, tienen un mismo contenido: la respuesta de Suárez a la condena de la Defensio fidei llevada a cabo por el Parlamento de París el 26 de junio de 1614. Tras una lectura atenta de los mismos se llega a la conclusión de que se trata en lo esencial de un mismo y único documento en dos versiones distintas (una latina y otra española), cuya fecha exacta de composición desconocemos, aunque sabemos que debió ser escrito entre la segunda mitad de 1614 y 1615. La identidad sustancial de los Acta et decreta y los Indicios y pruebas se deja ver claramente por el hecho de tener ambos una misma temática e incluso una misma estructura desarrollada en ocho epígrafes. Sin embargo, a pesar de ello, existen diferencias considerables entre ambos escritos, como vamos a ver en el epígrafe siguiente.

Desconocemos la razón de la existencia de estas dos versiones de la réplica de Suárez a la condena del Parlamento de París. En cualquier caso, una cosa es clara: tratándose de dos versiones de un mismo opúsculo, una ha de ser necesariamente el texto original y la otra una traducción posterior. Para determinar cuál de ambas versiones es la original y cuál la traducción posterior es preciso recurrir a diversas hipótesis más o menos plausibles. Sin duda lo más verosímil es pensar que el documento original es el latino (los Acta et decreta) y que la versión española (los Indicios $y$ pruebas) es una traducción posterior, sea del propio Suárez, realizada inmediatamente después, sea de otro autor, llevada a cabo más tarde. No hay que descartar, sin embargo, que la versión española haya sido escrita en primer lugar y que después fuera vertida al latín, a la vez que depurada lógicamente y mejorada desde el punto de vista léxico, como vemos que ocurre en el texto latino.

Aunque Suárez habla de sí mismo en tercera persona (propositiones Suarij, Suarius, Suarez), la autoría suareciana de ambas versiones, incluida la española, parece fuera de duda. En tal sentido, la versión española abunda en arcaísmos que coinciden con los usos lingüísticos del siglo XVII (como, por ejemplo, qual, exemptos, desto, dellos, quan, quatro, theologos, reyno, aprovacion, christiano, offreciendo, hereges, escriptores, catholicos, distinccion, presumption, etc.), así como algunos términos de sabor portugués (probança, endereçar, autoriçar). Ambos elementos apuntan inequívocamente a Suárez, un escritor español de entre los siglos XVI y XVII que pasó en Portugal los últimos veinte ańos de su vida. Sin embargo, ciertos rasgos del texto español que ha llegado hasta nosotros parecen indicar una datación posterior. En concreto, en varias ocasiones los Indicios y pruebas emplean la grafía ß (contracción de fs o ss) en palabras como proceßo en lugar de processo y el verbo latino poße en lugar de posse) y no consta que Suárez haya empleado la ß. Puede por ello que este documento sea una transcripción tardía del texto español de Suárez realizada tiempo después. En concreto, puede tratarse de una copia del texto original de Suárez 
realizada en el siglo XVIII, como Joaquim de Carvalho indica en la Nota preliminar de los Conselhos e pareceres.

En cualquier caso, las razones que nos mueven a pensar que la versión original es la latina (los Acta et decreta) (o que, al menos, la versión latina es la edición formal a la que iba encaminada la versión espańola, caso de haber sido escrita esta en primer lugar) son las siguientes:

a) Suárez era un teólogo profesional, cuyo vehículo de expresión habitual era el latín. En tal sentido, lo más lógico es pensar que el escrito original es el texto latino.

b) De otro lado, sería extraño que una réplica que aspiraba a ser una pública protesta de Suárez sobre la rectitud de su doctrina en un asunto que había alcanzado una enorme trascendencia internacional (en las cortes de Inglaterra, Francia, España, Venecia y Roma) se escribiera en español, limitando así la posibilidad de su conocimiento en otros países.

Sea, pues, por la naturaleza teológica de las cuestiones debatidas, sea por la audiencia internacional a la que, es de creer, iba dirigido el texto, el latín era el instrumento más adecuado para expresar la protesta frente al Parlamento de París. Prueba de ello es que no pocos párrafos de la versión espańola, como vamos a ver enseguida, están en latín, la lengua por otro lado en la que había sido escrita la Defensio fidei, cuya rectitud católica reivindicaba Suárez en esta réplica frente a la condena de París.

c) Una última razón, esta de índole interna, es que a diferencia de la versión española (en la que se constata una cierta informalidad sintáctica y un léxico más popular), la latina aparece dotada de mayor orden y concisión en los argumentos, de una sintaxis más cuidada y de un léxico más rico y preciso. Comparando ambas, la versión latina es con diferencia la mejor elaborada y por ello creemos que es bien la versión original (caso de haber sido escrita en primer lugar), bien la versión formal a la que iba encaminada la espańola (caso de haberlo sido posteriormente).

Sea de ello lo que fuere, el objeto principal de este trabajo es presentar una traducción propia de los Acta et decreta, que difieren no poco de la versión española, así como una anotación crítica de este breve texto latino, que, no se olvide, es la réplica de Suárez a la condena del Parlamento de París de su Defensio fidei. Insistimos en que, a pesar de la sustancial identidad de los Acta et decreta y los Indicios $y$ pruebas, las numerosas y abultadas diferencias que se dan en el contenido de los ambos documentos - como vamos a ver a continuación- justifican sobradamente, creemos, nuestro empeño de traducción del texto latino. De otro lado, no nos consta que estos Acta et decreta hayan sido traducidos al espańol con anterioridad ni, tanto menos, que hayan sido estudiados críticamente. 


\section{El texto latino de los Acta et decreta. Traducción y anotación crítica}

\begin{tabular}{|c|c|c|}
\hline $\begin{array}{c}\text { Texto latino } \\
\text { (Conselhos e pareceres, Coimbra } \\
\text { 1952, pp. } 217-221 \text { ) }\end{array}$ & $\begin{array}{c}\text { Traducción propia } \\
\text { al español }\end{array}$ & $\begin{array}{c}\text { Texto español } \\
\text { (Colleção Pombalina, ms. 243, } \\
\text { fol. 351, presentado por } \\
\text { L. Pereña, pp. 592-596) }\end{array}$ \\
\hline
\end{tabular}

Acta et decreta in Parlamento Pa-Actas y decretos del Parlamento de risiensi contra librum de fidei de- París contra el libro sobre la defensione Francisci Suarez damna- fensa de la fe de Francisco Suárez, bilem continere doctrinam contra [en los cuales] se contiene doctrina religionem catholicam, ideoque condenable contra la religión cadigna esse, ut per Ecclesiam dam- tólica y que por tanto son dignos nentur et probibeantur, ex eisdem de ser probibidos y condenados por actis his modis ostenditur'.

la Iglesia, como se prueba de este modo a partir de las mismas actas. prueba de mismo proceso ${ }^{2}$.

1.- Inter propositiones Suarij 1.- Entre las proposiciones de 1.- Primeramente, entre las prohanc ut damnabilem ponunt Suárez ${ }^{3}$ presentan $^{4}$ esta como posiciones de Suárez condenan propositio haec: condenable: es doctrina que hay y llaman damnable la siguiente: Papa potestatem habet ad depo- que aceptar y creer como dogma Propositio haec: Papa potestatem nendos Reges haereticos, et per- de fe que el Papa tiene potestad habet ad deponendos Reges haetinaces, suove regno in rebus ad de deponer a los reyes herejes y reticos, et perniciosos, suove Regno salutem animae pertinentibus pertinaces, dañosos para su reino in rebus ad salutem animae pertiperniciosos, inter dogmata fidei en las cosas tocantes a la salud del nentibus perniciosos, inter dogmatenenda, et credenda est.

alma 5 . Gritan ${ }^{6}$ que tal doctrina Illam ergo doctrinam pernicio- es perniciosa y digna de consam, et damnandam esse clami- dena. Y como Suárez confirma tant. Cumque Suarius expressa tal doctrina con la definición definitione Bonifacij VIII. illam confirmaverit, nihil illi respondent, taciteque Pontificis sententiam sub eadem damnatione comprehendunt. Et e converso Rogerij disputationem, quam infra commemorabimus, cuius scopus, et fundamentum solum est, non esse dogma fidei, Pontificem habere huiusmodi potestatem, omnino approbant, ac totis viribus defendunt. expresa de Bonifacio VIII ${ }^{7}$ y nada le responden, vienen así a incluir tácitamente la sentencia de este Pontífice bajo la misma condena. $Y$ en sentido contrario aprueban y defienden con todas sus fuerzas la disputación de Roger $^{8}$, a la que nos referiremos más abajo, cuyo único propósito y fundamento es negar que sea ta fidei tenenda et credenda est. De lo qual consta que tienen esta doctrina por damnable. Y siendo así que refieren la definición de Bonifacio VIII, que Suárez allega, ninguna cosa le responden, y así parece que tácitamente la comprehenden in eadem damnatione; y al contrario aprueban la doctrina de Rogerio, cuyo fundamento es, no ser de fe que el Papa tenga tal potestad, de cuyo libro más abajo se hará más expresa mención.

dogma de fe que el Pontífice tiene tal potestad. 
2.- Inter propositiones Suarij, 2.- Entre las proposiciones de 2.- Lo mismo consta del prinquas in principio accusationis Suárez a las que en el principio cipio de la acusación contra damnabiles vocant, primo fere de la acusación llaman condena- Suárez, donde entre las propoloco hanc ponunt: Pontifex Sum - bles, ponen en primer lugar esta: siciones, que llaman damnables, mus potestate coerciua in Reges uti El Sumo Pontifice puede intervenir ponen en primer lugar esta: potest, usque ad depositionem a con potestad coercitiva frente a los Pontificem Summum potestate regno, si causa subsistat. Et om- reyes hasta la deposición del reino, nes fiscalis criminationes, et exa- si la causa [que motiva dicha inggerationes contra praedictum tervención] persiste ${ }^{9}$. Y todas las Suarez nihil aliud continent, si acusaciones y las exageraciones attente considerentur, nisi im- del fiscal contra el referido Suárez pugnationem, et detestationem no contienen otra cosa, si se conillius doctrinae, et potestatis, ut sideran atentamente, sino la imex repetitione plurium similium pugnación y la condena de aquepropositionum, et ex toto dis- lla doctrina de la potestad [del cursu accusationis manifestum Papa], como es manifiesto por la est.

repetición de otras muchas proposiciones semejantes y por todo el discurso de acusación.

3.- Hanc eorum mentem non 3.- Aquellas palabras con las 3.- Esto se declara más en un parum declarant verba [218] que dicen de Suárez que querría modo de hablar, que tienen de illa, in quibus de Suario dicunt, excluir a los reyes de España de la la jurisdicción pontificia, llavoluisse a praetensa Pontificia pretendida jurisdicción del Pontí- mándola jurisdicción pretensa, iurisdictione Reges Hispaniae fice ponen en buena medida de que claramente se condistinexcipere. In quibus verbis nunc manifiesto su pensamiento ${ }^{10}$. En gue de jurisdicción verdadera o non consideramus calumniam, esas palabras no consideramos qua Suario, contra illius men- ahora la calumnia con la que, tem, immo contra expressa eius contra la mente de Suárez, incluverba generalia, et sine ulla vero- so contra sus expresas palabras en simili coniectura, exceptionem general y sin verosimilitud alguillam attribuunt, nam illa non na, [le] atribuyen aquella excepidcirco exemplum in Regibus Hispaniae non adhibuit, quia Reges Hispaniae a subiectione Pontificis exemptos esse putauerit, sed quia simile exemplum in historijs non inuenit, et quod adduci poterat ex quodam Lusitaniae Rege, non praetermisit. Veruntamen, ut dixi, de calumnia nunc nihil agimus, sed consideramus solum particulam illam diminuentem, praetensa ción, puesto que dicha [excepción] no se puso como ejemplo de los reyes de España por esta razón, como si [Suárez] considerara que los reyes de España estuvieran exentos de la sujeción del Pontífice, sino porque no encontró ejemplo semejante en la historia, y [porque] no dejó pasar el [ejemplo] que podría ser aducido de cierto rey de Lusitania. Sin embargo, como dije, no tratamos coerciva in Reges uti posse usque ad depositionem a regno, si causa subsistat. Lo qual prosiguen y repiten muchas veces. Antes si atentamente se leen las criminaciones con que se refieren y repiten las proposiciones del dicho Suárez, todas van endereçadas a negar esta potestad al Papa.

cierta. Esto se ve en la calumnia que imponen a Suárez, diciendo que quiso exceptuar a los Reyes de España de la pretensa jurisdicción pontificia. En lo qual no reparamos ahora en lo que dicen de Suárez, aunque consta ser manifiesta calumnia, pues es contra sus palabras universales, y sin fundamento. Porque si no puso exemplo en los Reyes de Espańa, no es porque pensase ser exemptos sino porque o no lo hay en las historias o él no lo sabe y así lo que supo y se escribe de un rey de Portugal no lo dexo. Mas dexando esto, ponderamos el modo de hablar con addito 
iurisdictione, nam manifeste ab aquí de la calumnia, sino que accusatoribus Suarij addita est, consideramos únicamente aquene talem iurisdictionem Pon- lla partícula que menoscaba [ditifici tribuere, eamve confiteri cha potestad pontificia], a saber, viderentur; non enim ob aliam la pretendida jurisdicción, porque causam non simpliciter iurisdic- ha sido añadida por los acusadotionem, sed praetensam iurisdic- res de Suárez manifiestamente tionem Pontificiam appellarunt.

para no reconocer tal jurisdicción diminuente de la jurisdicción del Papa llamándola pretensa. Porque los que así hablan, claramente han dado a entender que no la tienen por cierta, ni aun por verdadera. al Pontífice o para que no parezca que se le reconoce, pues en efecto no por otra causa no la llamaron simplemente jurisdicción, sino pretendida jurisdicción Pontificia.

4.- Magnum etiam eiusdem 4.- Un indicio claro también de doctrinae indicium est, quod esta manera de pensar es que cum Rogerius Vuidringtonus cuando Roger Widdrington pudisputationem theologicam edi- blicó la disputación teológica soderit de iuramento fidelitatis, bre el juramento de fidelidad, a quae Romae, et in Hispania perniciosae, et haereticae doctrinae damnata est, nihilominus ille auctor, et doctrina eius contra Pontificis potestatem, in illis actis probatur, et defenditur. Nam fiscalis regius fere in fine accusationis suae quendam theologum reprehendit eo quod apologiam eiusdem Rogerij pro iure Principum tanquam fidei catholicae repugnantem in quadam epistola sua fuerit criminatus. In qua reprehensione fiscalis ille plane contendit, doctrinam Rogerij ut catholicam, et verae fidei consentaneam tueri. Quam fiscalis intentionem cum omnibus in eius accusatione contentis parlamentum in suo decreto, seu arresto manifeste probauit, illique consensit. pesar de ser condenada en Roma y en España como doctrina perniciosa y herética, sin embargo tanto aquel autor como su doctrina contra la potestad del Pontífice fueron defendidos y aprobados en el [correspondiente] proceso [de París]. En efecto, el fiscal real ${ }^{11}$, casi al final de su acusación, censura a cierto teó$\operatorname{logo}^{12}$ por haber acusado en una carta suya de ser repugnante a la fe católica la apología del mismo Roger en favor del derecho de los príncipes. En aquella reprensión el fiscal se esfuerza claramente en mostrar la doctrina de Roger como católica y en defenderla como acorde con la verdadera fe. Y como quiera que todos [en el Parlamento] se unieron a aquella acusación según la intención del fiscal, el Parlamento en su decreto o proceso también consintió y aprobó manifiestamente.
4.- Desto es también manifiesto indicio, que aviendo escrito un inglés llamado Rogerio Widrington una disputa Theologica de Iuramento fidelitatis de damnable doctrina en esta materia de Potestate Pontificis, como está declarado en Roma y en España con prohibición del dicho libro; con todo eso en estos actos de Francia se defiende y ampara este autor con su doctrina, como se ve del fin dellos, donde el fiscal o agente del Rey reprehende a un Theologo catholico, porque en una carta condena la doctrina del dicho Rogerio en una Apologia pro iure principum como repugnante a la fe catholica. De lo qual consta claramente, que el dicho fiscal aprueba y defiende la doctrina del dicho Rogerio con el cual consiente claramente el Parlamento, aprobando todas estas criminaciones, y reprehensiones del fiscal. 
5.- Attente considerandum est, 5.- Hay que considerar atenquod licet inter criminationes tamente que, aunque entre las contra Suarium controuersiam acusaciones contra Suárez se rede tyrannicidio interponant, et fieran a la controversia sobre el de doctrina eius etiam in hac tiranicidio y se deplore su docparte conquerantur, nihilomi- trina al respecto, sin embargo nus ex discursu accusationis non del texto de la acusación se deobscure colligitur, hoc tantum duce sin gran dificultad que esto factum esse ad suam praeci- se hace solo para disimular ${ }^{13} \mathrm{su}$ puam intentionem oppug|nandi [219] Pontificiam potestatem occultandam. Nam in doctrina Suarij de tyrannicidio nihil animaduertunt, quod ad punctum controuersiae de occisione veri Principis pertineat. Quanuis enim in primis animaduertant, quod Suarius in principio suae disputationis supponit: Quaestionem, quae tractatur, esse praecipue de legitimo Principe tyrannice gubernante, non tamen ulterius progrediuntur, sed dissimulant. Debuissent enim ingenue fateri, resolutionem et assertionem Suarij esse, non esse licitum subdito, legitimum Principem occidere, etiamsi tyrannice gubernet. Immo assertionem hanc, quae ad rem pertinebat, subticendo, solum notant, quod Suarez scripserit, contingere posse, ut si verus Princeps manifesta vi, et iniusta subditum interficere velit, possit subditus se, vel patriam iuste defendere, etiamsi mors Principis inde sequatur. Cum tamen hoc nec seditionibus, aut perturbationibus occasionem praebeat, neque in dubium ab aliquo vocatum sit. Vnde obiter animaduerto, fiscalem in principio accusationis suae conquestum de Suario fuisse, quod in libro
5.- Para que estos indicios, $y$ otros no se confundan, o obscurezcan con lo que en el dicho proceso se mezcla de la controversia y doctrina del tyrannicidio, se a de considerar atentamente, que de los mismos autos se colige, que esto fue solo para colorear, y exagerar su quexa, y principalmente para disimular y encubrir su principal intento, que es repugnar a la verdadera doctrina de la potestad del Papa. Porque en el principio de su quexa notan en Suárez, que presupone, quaestionem quae tractatur, esse praecipue de legitimo Principe tyrannice gobernante, y no ańaden, que la conclusión, que pone, es, que no es lícito al súbdito matar al legitimo Príncipe, aunque govierne tyrannicamente. Y después sólo notan, que in actuali aggresione iniusta facta a principe potest interdum subditus defendere vitam propriam vel patriae, etiamsi inde sequatur mors principis. Lo qual es omnino extra quaestionem, y no puede ser ocasión de sediciones o perturbaciones. De donde se collige, quan sin causa aviendose quexado el fiscal, al principio, que ay en el libro de Suarez proposiciones contrarias al poder de los príncipes y Reyes soberanos, entre ellas pone esta de la propia defensión, como si perteneciese a la potestad de los príncipes soberanos matar injustamente a sus vasallos, y si esto pretenden, caen en un gravísimo error, y [si no se ve claramente que se puso] aquello para hacer sombra a todo lo demás. Porque luego se 
suo multa contra potestatem supremam Regum, ac Principum scripserit, inter quae postea hanc jo de propria defensione subditi criminatur. In quo vel supponit, habere supremos Principes potestatem expugnandi, et aggrediendi subditus vsque ad fen internicionem sine iusta causa, sup quod non est credibile, cum sit patentissimus error: vel si hoc non supponit, sine causa, quae hasta la muerte sin justa causa, vere subsistat, conqueritur de lo que no es creíble, porque es doctrina illa, quae subdito ius- un error patentísimo; o si no tam defensionem concedit. Ex supone esto, deplora sin causa quo tandem manifeste concludi- que verdaderamente subsista tur, totam illam partem accusa- aquella doctrina que concede al tionis, quae ad controversiam de súbdito la justa defensa. De ello, tyrannicidio pertinet, fucatam, finalmente, se concluye maniet apparentem tantum fuisse ad fiestamente que toda la parte praecipuam intentionem suam de la acusación que se refiere a impugnandi Pontificiam iuris- la controversia sobre el tiranicidictionem, occultandam. Vnde dio está adulterada para ocultar post leuem illam animaduersio- la que parece haber sido únicanem circa tyrannicidium, statim mente su [del fiscal y del Parlaad impugnandas propositiones, mento] intención principal, a quibus Pontificia iurisdictio saber, impugnar la [doctrina] defenditur, reuertitur, et in hoc de la jurisdicción pontificia. De vsque ad finem accusationis per- ahí que después de aquella ligera sistit. observación sobre el tiranicidio, tornan a formar quexas de todo lo que se dice de la jurisdicción papal, y en esto perseveran hasta el fin de esta acusación. se retorna de inmediato a la impugnación de las proposiciones que defienden la jurisdicción Pontificia y así persiste la acusación hasta el final. 
6.- Dignum est magna animaduersione, et consideratione, quanta libertate, et facilitate acta illa auctoritatem et approbationem quattuor grauissimorum episcoporum Portuga|liae [220] eos etiam recensendo, contemnant nimirum Conimbricensis, Algarbiorum, et Lamecensis, qui y Lamego, gravísimos teólogos Algarbiorum, et Lamecensis, qui y Lamego, gravísimos teólogos
tres grauissimi theologi sunt, et e insignes en prudencia y reliprudentia, ac religione insignes, gión, y un cuarto, doctísimo en quartus vero est in iure canonico doctissimus, simulque supremus in Portugallia inquisitor, et tunc vice Regius eiusdem regni gubernator. Atque eodem modo approbationem Vniuersitatis Complutensis adeo despiciunt, vt neque aliquam eius mentionem faciant, neque septem doctorum theologorum, qui eius approbationi subscribunt, et de communi Vniuersitatis consensu his grauissimis verbis testificantur. Nibil est in toto hoc opere ab omnium nostrum sensu discordans, cum de hac re sit omnium nostrum eadem vox, idem animus, eademque sententia. Ex quo non leue indicium sumitur, eos, qui audent tam graue, constans et commune iudicium doctorum, et pastorum catholicorum ita contemnere, ut damnabilia, et detestanda esse dicant, quae $\mathrm{ab}$ ipsis tam grauiter approbata sunt, etiam a doctrina communiter in Ecclesia approbata discordare, velleque noua dogmata contra supremam auctoritatem pontificiam ${ }^{15}$ Christo datam introducere.
6.- Digno de gran atención y consideración es [ver] con cuanta libertad y facilidad desprecian aquellas actas la autoridad y la aprobación de cuatro de los más graves obispos de Portugal, a quienes también citan, a y aber, los de Coimbra, Algarve gión, y un cuarto, doctísimo en
derecho canónico a la vez que supremo inquisidor en Portugal y entonces virrey $[\mathrm{o}]$ gobernador del mismo reino ${ }^{16}$. Del mismo modo menosprecian [aquellas Actas] la aprobación de la Universidad Complutense hasta el punto de no hacer mención bación] de los siete doctores teólogos que la suscriben. Del común consenso de [esta] Universidad [dichos teólogos] dan fe con estas gravísimas palabras: Nada hay en toda esta obra que resulte contrario a nuestro parecer, teniendo todos nosotros sobre esta cuestión la misma palabra, la misma opinión y el mismo juicio. De todo lo cual resulta una prueba no pequeńa de que aquellos que osan tan gravemente despreciar así el juicio constante y común de los doctores y pastores católicos considerando como digno de condena y detestable aquellas cosas que tan gravemente han sido aprobadas por los mismos, se apartan de la doctrina comúnmente aprobada en la Iglesia y quieren introducir nuevos dogmas contra la suprema autoridad pontifica dada por Cristo. alguna de ella ni de la [apro-
6.- Es mucho de ponderar la facilidad, con que desprecian la aprobación de quatro obispos gravissimos de Portugal, nombrándolos expresamente, siendo los tres dellos theologos y hombres muy antiguos, y de grande experiencia, y religión; y el quarto es muy docto canonista con las otras partes dichas, y inquisidor mayor deste Reyno, y entonces Virey en él. Y con mayor desprecio no hicieron caso de la Universidad de Alcalá, ni de siete graves Doctores theologos que suscriben su aprovacion y testifican ser común consentimiento de aquella Universidad con aquellas gravissimas palabras: Nibil est in toto hoc opere ab omnium nostrum sensu discordans, cum de hac re sit omnium nostrum eadem vox, idem animus, eademque sententia. De lo qual se collige, que quien se opone a tan común y constante juicio de los Doctores y Pastores católicos, condenando su doctrina por damnable, dan gran sospecha de apartarse del común sentimiento de la Iglesia católica, y que quieren introducir doctrina nueva digna de ser reprobada, y prohibida. 
7.- Jn hoc genere multum pias aures offendunt verba, quibus speciatiter in episcopum Algarbiorum inuehuntur, eumque reprehendunt, et quandam eius sententiam censura dignam appellare audent. Refert enim ille in approbatione sua, Clodoueum primum Galliae christianum Regem Hormisdae Papae coronam regiam misisse, quod sciret (inquit) vnicum esse totius Ecclesiae visibile caput, quo facto oppignorauit regnum Gallorum in Ecclesiae Romanae praesidium, pariterque et obsequium ${ }^{17}$. Quae verba etiam parlamentum in suo decreto tanquam falsa, et calumniosa condemnat. Cuius censurae causam, et rationem inquirimus, eamque sine aliqua prauae doctrinae suspitione dari posse non credimus. Nam si falsam appellant, quia veritatem illius historiae negant, videbuntur in hoc profecto haereticorum morem imitari, vel etiam fouere, illi enim ecclesiasticas historias [221] etiam perantiquas, et graues, qualis haec est, facile contemnunt, si traditionem, et vsum supremae potestatis Sedis Apostolicae confirmet. Si vero non obstante veritate historiae piam episcopi interpretationem, et accommodationem calumniosam appellant, profecto non recte de Pontificia dignitate sentire, et nolle, ut a Regibus temporalibus ut vere superior recognoscatur, indicant.
7.- En este asunto ofenden mucho a los píos oídos las palabras de desaprobación dirigidas especialmente contra el obispo del Algarve, a quien reprenden, osando llamar digna de censura a una sentencia suya en la que [este obispo] refiere como confirmación [de su doctrina] que Clodoveo, el primer rey cristiano de la Galia, envió la corona regia al Papa Hormisdas, reconociendo-dice [el obispo]-que uno solo es la cabeza visible de toda la Iglesia, por lo que dio en prenda el reino de los galos a la Iglesia de Roma como protección, a la vez que como obsequio. También el parlamento condena estas palabras en su decreto como falsas y calumniosas. [Pero] buscando la causa y el motivo de esta censura, no creemos que se pueda dar sin sospecha de doctrina depravada. Pues si la llaman falsa, porque niegan la verdad de aquella historia, parecen imitar de esta manera la costumbre de los herejes ${ }^{18} \mathrm{o}$ incluso abrazarla, pues desprecian fácilmente las historias eclesiásticas, incluso las más antiguas y graves, como es esta, si confirman la tradición y el uso de la suprema potestad de la Sede Apostólica. Si, en cambio, admiten la verdad de la historia, pero llaman calumniosa a la pía interpretación y acomodación del obispo, muestran no sentir rectamente de la dignidad pontificia y no querer que [dicha potestad] sea reconocida como verdaderamente superior por los reyes temporales.
7.- En lo qual especialmente offendit pias aures todo lo que dicen contra el Obispo del Algarve, llamando una cosa o advertencia suya, digna de censura, solo por la historia que refiere de Clodoveo primero Rey christiano de Francia, que envió una corona al Papa Hormisdas ${ }^{19}$, reconociendo por este don su potestad y autoridad Pontificia, y offreciendole su Reyno en presidio y en obsequio. Las quales palabras condena el Parlamento en su sentencia por falsas y calumniosas. En la qual censura si pretenden negar la verdad de la historia, dan mala sospecha de si, imitando [a] los hereges, que fácilmente niegan las historias ecclesiasticas por antiguas y graves que sean, como esta lo es, solo por redundar en autoridad de la Sede Apostólica. Y si admitiendo la verdad de la historia tienen por calumnia la pía interpretación o significación, que el dicho obispo añade, muestran claramente no sentir bien de la dignidad pontificia, ni querer que sea reconocido de los Reyes temporales por superior. 
8.- Vltimo in his actis animaduertimus, solum in eis reprehendi scriptores catholicos, eosque plures, et graues, et praesertim illos, qui pro defendenda Sede Apostolica, eiusque auctoritate contra haereticorum audaciam, et insolentiam scripserunt, quales sunt Bellarminus, Becanus, Lesius, et frater Leonardus Coqueau. Quibus adiungunt Vazquez, et Azor, et in vniuersum alios Societatis Jesu scriptores, solum quia in suis scriptis theologicis pro vera Summi Pontificis dignitate, et potestate constanter pugnant. Jdeoque fiscalis in accusatione sua inter alia ponderat illa verba Suarij: Omnes nos in hac causa vnum sumus, quae verba tractando de suprema potestate spirituali Pontificis scripsit, quod fiscalis callide subticuit. Atque eodem certe nomine Spondeum expresse, et tacite Baronium reprehendunt, non certe alia de causa, nisi quia in sua historia praedictam Pontificis potestatem varijs exemplis, et signis confirmant. Et e conuerso auctores, qui de contraria doctrina male audiunt defenderé conantur, ut de Rogerio notaui. Et quanuis cum prioribus catholicis auctoribus alios, qui de tyrannicidio scripserunt, coniungant, illud fecisse videntur, ut notaui, ne solos defensores Pontificiae potestatis accusare viderentur. Materia enim illa longe diuersa est, et in libro Suarij, propterquem tempestas haec orta est, solum obiter attingitur, et tanta distinctione, et circunspectione
8.- Finalmente observamos que en estas Actas se reprende solamente a muchos y graves escritores católicos, sobre todo a aquellos que escribieron en defensa de la Sede Apostólica y de su autoridad contra la audacia e insolencia de los herejes, como son Belarmino ${ }^{20}$, Becano ${ }^{21}$, Les$\operatorname{sio}^{22}$ y el hermano Leonardo Coqueau $^{23}$, a los que añaden Vázquez $^{24}$, Azor $^{25} \mathrm{y}$ en general a otros escritores de la Sociedad de Jesús solamente porque en sus escritos teológicos se muestran constantemente partidarios de la verdadera dignidad y potestad del Sumo Pontífice. Y por ello el fiscal se refiere en su acusación entre otras cosas a aquellas palabras de Suárez: todos nosotros en esta causa somos una sola $\cos a^{26}$, que escribió refiriéndose a la suprema potestad espiritual del Pontífice, pero el fiscal astutamente lo disimula. Y ciertamente por la misma razón censuran expresamente a Spondeo ${ }^{27}$ y tácitamente a Baronio ${ }^{28}$ no por otra razón sino porque [ambos] confirman la referida potestad del Pontífice con varios ejemplos $y$ datos en su[s obras de] historia. Y, al contrario, se esfuerzan en la defensa de los autores de doctrina contraria, a los que desgraciadamente prestan oídos, como ya observé sobre Roger. Y aunque mezclan a los anteriores autores católicos con otros que escribieron sobre el tiranicidio, parecen proceder así, como ya indiqué, para que no parezca que los acusan solamente de ser defensores de la potestad Ponti-
8.- Últimamente se debe notar en estos Actos, y sentencia, que en ellos no se reprehenden sino escriptores catholicos, y estos muy graves y en mucho [número y en obras que han escrito contra los herejes y en defensa de la Sede Apostólica y su autoridad como son] Bellarmino, Becano, Fray Leonardo Coqueau, Lesio, y a éstos añaden también Vázquez y Azor, sólo porque en sus obras enseñan la verdadera doctrina de la autoridad pontificia, y sienten mal de que Suárez diga Omnes nos in hac causa unum sumus, lo qual dixo tratando de suprema potestas espiritual del Papa, y por el mismo título calumnian a Spondeo, y tácitamente a Baronio, porque en su historia siempre van mostrando y confirmando esta potestad. Y al contrario pretenden autoriçar, y defender los Autores reprobados, como es Rogerio, y otros semejantes. Y para dar más color a su intento, juntan con estos los autores que an escrito de tyrannicidio, siendo materia muy differente, y que no se toca en el libro de la defension catholica de Suárez, sino muy acaso, y con tanta distinccion y recato, que a ninguno bien intencionado, y que sienta bien de la autoridad de la Sede Apostólica puede ofender. Y así queda en su fuerça el dicho mal indicio. $Y$ de todos juntos resulta mas que evidente presumpcion y sufficiente probança de la perniciosa doctrina y digna de ser reprobada, que en los dichos Actos se contienen. 
definitur, ut neminem recte de ficia. Pues aquella materia [es potestate Pontificis sentientem, decir, el tiranicidio] es bien diset puro, ac syncero animo pro- tinta de esta otra [sobre la pocedentem possit offendere. Ex testad pontificia], y en el libro his ergo indicijs omnibus non de Suárez, por causa del cual se solum vehemens praesumptio, ha originado esta tempestad, sed etiam sufficiens probatio solamente se trata de tal materia concludi videtur, quod doctrina [es decir, el tiranicidio] de paso, in illis actis contenta omnino definiéndola y [tratándola] con damnanda, et interdicenda esse tanta distinción y circunspecvideatur.

ción que a nadie que sienta rectamente de la potestad del Pontífice y que proceda con ánimo puro y sincero puede ofender. Así pues, de todos estos indicios parece concluirse no solo una presunción vehemente, sino también una prueba suficiente de que la doctrina contenida en aquellas Actas parece deba ser completamente prohibida y condenada. 
Finalmente, dada la unidad de temática, presentamos también al final de este trabajo la censura teológica de Belarmino sobre la condena parisiense de la Defensio fidei suareciana.

3. El texto latino de la censura teológica de Belarmino de la condena de Suárez. Traducción y anotación crítica

Al igual que los ACTA ET DECRETA de Suárez, tampoco la censura teológica de Belarmino de la condena de Suárez por parte del Parlamento de París ha sido traducida al español. Esta es, pues, la primera traducción que se pone a disposición del público de lengua española de este breve documento.

El texto que presentamos y traducimos pertenece al género de la censura teológica, caracterizado por la concisión y asertividad. El texto está estructurado en seis puntos relativos a las cuestiones siguientes: 1) la jurisdicción exclusiva de los obispos en materia de doctrina de fe, contra la injerencia del Parlamento de París; 2) la valoración de la tesis de la suprema potestad regia, aceptada en parte (en cuanto que en lo temporal el rey no tiene superiores) y en parte rechazada (en cuanto que el Papa tiene una potestad real, aunque indirecta, en los asuntos temporales del reino, si se pone en peligro el bien espiritual de los súbditos cristianos); 3) la reivindicación del buen nombre de Suárez, quien con la tesis de la potestad indirecta del Papa in temporalibus no ha hecho sino reiterar la doctrina de grandes teólogos nunca condenados en Francia (como Agustín, Tomás, Soto, Azpilcueta, etc.); 4) recusación del proceso del Parlamento de París como falso y calumnioso, liberando a Suárez de esta misma acusación dirigida contra él por el Parlamento, en relación con la mención de los episodios históricos de los reyes franceses Clodoveo y Felipe el Hermoso; 5) denuncia de la injusta proscripción del libro de Suárez, dado que en París son permitidos muchos libros, incluso de los calvinistas, donde se sostiene y justifica el regicidio; 6) condena como intolerable de la prohibición bajo pena de lesa majestad de la tesis suareciana de la potestad temporal indirecta de Papa. 
1. Summa observationis in arrestum Parlamenti Parisiensis contra Franciscum Suarezium.

Arrestum caret auctoritate, quia iudicare de doctrina pertinet ad Episcopos, non ad Parlamenta.
1. Juicio resumido sobre el proceso del Parlamento de París contra Francisco Suárez.

El proceso carece de autoridad, porque juzga sobre una materia que compete a los obispos, no a los Parlamentos.

2. Titulus ubi dicitur esse in libro P. Suarez multas propositiones contra supremam potestatem regiam, vel est falsus, vel erroneus. Nam si sensus sit propositiones illas esse contra potestatem regiam, quia Suarez subiiciat Reges Pontifici in tempotalibus directe, quasi Papa sit Rex Regum, titulus falsus est manifeste, quia Suarez fatetur Reges non habere superiorem in temporalibus directe; si vero sensus sit de potestate Papae in spiritualibus directe et indirectae in temporalibus, propositiones sunt verissimae et comunes apud catholicos, et deductae ex Scriptura et Conciliis. Proinde erroneus est titulus ille.

3. Ubi dicit Arrestum propositiones illas esse scandalosas et seditiosas, falsum dicit. Nam Suarez allegat ubique suos auctores antiquos et $\mathrm{ab}$ omnibus probatos, S. Augustinum, S. Thomam, Sotum, Navarrum et alios multos, quos nemo hactenus dixit scandalosam aut seditiosam doctrinam tradidisse.

4. Ubi dicit falsum esse et calumniosum quod Suarez scribit de regibus Clodovaeo et Philippo Pulchro, ipsum Arrestum falsum est et calumniosum. Nam Suarez refert a Clodovaeo missam fuisse ad Papam coronam de lapidibus pretiosis, quae
2. El capítulo donde se dice que en el libro de Suárez hay muchas proposiciones contra la suprema potestad regia es o falso o erróneo. En efecto, si el sentido de tales proposiciones [de Suárez] es contra la potestad regia, en el sentido de que somete a los reyes al Pontífice directamente en los asuntos temporales, como si el Papa fuera un Rey de Reyes, el capítulo es manifiestamente falso, porque Suárez dice que los reyes no tienen directamente superior alguno en los asuntos temporales. $\mathrm{Si}$, en cambio, el sentido [de tales proposiciones] se refiere a la potestad del Papa en los asuntos espirituales directamente e indirectamente en los temporales, tales proposiciones son verdaderísimas, comunes entre los [autores] católicos y deducidas de la Escritura y de los Concilios y por tanto el capítulo aquel es erróneo.

3. Donde el proceso dice que aquellas proposiciones [de Suárez] son escandalosas y sediciosas, se expresa con falsedad. Pues Suárez cita en muchos lugares a diversos autores antiguos y aprobados por todos, como san Agustín, santo Tomás, Soto, el [doctor] Navarro [es decir, Azpilcueta] y otros muchos, de los cuales nadie hasta ahora ha dicho que trasmitieran una doctrina escandalosa o sediciosa.

4. Donde [el Parlamento] dice que es falso y calumnioso lo que Suárez escribe acerca de los reyes Clodoveo y Felipe el Hermoso, en realidad es el propio proceso quien se expresa de modo falso y calumnioso. Pues Suarez refiere que Clodoveo 
dicitur Regnum; et hoc expresse tradit Anastasius bibliothecarius in vita Hormisdae Papae. De rege Philippo Pulchro dicit Suarez quamdam eius epistolam ad Bonifacium Papam VIII esse ineptam, et vere dicit; haec enim sunt verba epistolae in Annalibus Franciae Nicolai Gillii: "Philippus Rex francorum Bonifacio qui se gerit pro Pontifice, salutem modicam sive nullam: sciat maxima, fatuitas vestra nos in temporalibus nulli subesse". Salutationem huius epistolae Rex Angliae in sua praefatione monitoria vocat ridiculam, et Paulus Aemilius in vita Philippi Pulchri totam epistolam vocat ignominiosam. Non igitur calumniosa sunt verba Suarez cum illam vocat ineptam, quod est minus quam ridiculam aut ignominiosam. envió al Papa una corona de piedras preciosas, a la que se llama Reino; y tal cosa muestra expresamente el bibliotecario Anastasio en la vida del Papa Hormisda ${ }^{29}$. Sobre el rey Felipe el Hermoso dice Suárez que una cierta carta suya [dirigida] al Papa Bonifacio VIII es inepta y dice [así] con verdad. En efecto, estas son las palabras de la carta [de Felipe el Hermoso] según los Annales de Francia de Nicolás Gilles: "Felipe, rey de los francos, a Bonifacio, quien se hace pasar por Pontífice, salud poca o ninguna. Sepa vuestra máxima fatuidad que nosotros en los asuntos temporales no estamos bajo [la potestad] de nadie" ${ }^{30}$. El propio rey de Inglaterra llama ridículo al saludo de esta carta en su Prefacio monitorio ${ }^{31}$ y Pablo Emilio, en su vida de Felipe el Hermoso ${ }^{32}$, llama a toda la carta ignominiosa. No son, por tanto, calumniosas la palabras de Suárez cuando la llama inepta, lo cual es menos que [llamarla] ridícula o ignominiosa.
5. Ubi Arrestum iubet librum Suarez non posse haberi, vendi, legi, sed comburi, etc..., iniustum est manifeste, nam nihil docet Suarez quod non docuerint optimi auctores qui passim leguntur Parisiis, immo Parisiis habentur, venduntur, leguntur et non comburuntur plurimi libri haereticorum et eorum etiam qui docent posse occidi principes ad introducendum vel stabiliendum Calvinismum, ut agnosci potest ex responsione calumniarum Anticotonis.

6. Ubi iubet Arrestum legi et publicari hoc suum decretum singulis annis in collegio Sorbonae et Claromontano et monasteriis Ordinum mendicantium et observari sub poena laesae Maiestatis, si Arrestum iuberet solum quot annis legi et observari decretum Concilii Constantiensis de occisione tyranni, non posset reprehendi, sed quod iubeat quotannis publicari propositiones Suarez de potestate Papae, et prohiberi sub poena laesae Maiestatis de illis disputari, eas legere vel tenere,
5. Donde el proceso manda que el libro de Suárez no pueda ser tenido, vendido, leído y que deba ser quemado, etc. ..., es manifiestamente injusto, pues Suárez nada enseña que no hagan autores óptimos que son leídos por todas partes en París, donde incluso son tenidos, vendidos y leídos, y no quemados, multitud de libros de los herejes y de aquellos que también enseñan que se puede dar muerte a los príncipes [con el propósito] de introducir y establecer el calvinismo, como se puede reconocer por la respuesta de las calumnias del Anti-Coton ${ }^{33}$.

6. Donde el proceso manda leer y publicar este decreto suyo cada año en el colegio de la Sorbona y en el Claromontano ${ }^{34}$ y en los monasterios de las órdenes mendicantes y que sea observado bajo pena de lesa Majestad, si el proceso mandara solamente que se leyera todos los años y se observara el decreto del Concilio de Constanza sobre la occisión del tirano, no podría ser reprehendido. Pero lo que manda sobre la obligación de publicar cada año las proposiciones de Suárez sobre la 
etc...., est prorsus intolerabile, hoc enim est claudere ora defendentium Pontificis potestatem, et aperire ora eam lacerantium et blasphemantium. Et pareterea est dare occasionem malignis hominibus capiendi in sermone simplicis et bonos viros, eosque ad iudicium et poenam capitalem innocentes trahere. potestad del Papa con la prohibición de que se dispute acerca de ellas bajo pena de lesa Majestad, así como también leerlas y tenerlas, etc..., es completamente intolerable, pues tal cosa es cerrar las bocas de los que defienden la potestad del Pontífice y abrir las de aquellos que la dañan y blasfeman contra ella. Más aún, es dar ocasión a hombres malvados de inducir a error por medio de la palabra a los hombres sencillos y buenos y arrastrar a los inocentes al juicio y a la pena capital.

\section{Valoraciones conclusivas}

Pasemos ya a unas valoraciones conclusivas, parte final de este trabajo.

1) No cabe duda de que el núcleo fundamental de la Defensio fidei repudiado por la condena del Parlamento de París era la doctrina de la potestad indirecta del Papa in temporalibus. Así lo hacía saber el canciller francés Sillery, católico y amigo de Roma, al Nuncio en París, Ubaldini, a quien manifestó, cuando tuvo noticias de la llegada a París de la Defensio fidei, que cualquier libro que defendiera dicha tesis sería rechazado en Francia ${ }^{7}$. Un motivo ulterior se añadía en Francia a la condena de la Defensio fidei: en ella se sostenía con firmeza la idea del origen popular del poder $y$, en consecuencia, del sometimiento y control del rey al pueblo y al pacto constitucional de cesión del poder. Como quiera que la teoría política francesa, digamos oficial, se sustentaba sobre el principio del origen divino del monarca, al igual que en la Inglaterra de los Estuardo, el conflicto entre las cortes francesa e inglesa y la teoría política de los jesuitas resultaba necesariamente inevitable. Conviene recordar que las medidas adoptadas en Francia contra la Defensio fidei habían sido instadas desde Inglaterra por Jacobo I, quien entregó al embajador francés en Londres unos excerpta de la Defensio fidei que contenían textos que Jacobo I consideraba lesivos e inaceptables para la autonomía e independencia política de Inglaterra y que estimaba serían igualmente entendidos en Francia.

\footnotetext{
7 Cf. Ubaldini al card. Borghese, 31 de diciembre de 1613, Archivo Vaticano, Nunziatura di Francia, t. 55, fols. 507-509, cit. por Scorraille, R. de, El P. Francisco Suárez de la Compañía de Jesús, Pamplona, Analecta, vol. II, 2005, p. 189
} 
2) El rechazo de la potestad indirecta del Papa en Inglaterra estaba presente desde antiguo, pero resurgió con fuera tras la escisión protestante, iniciada en Inglaterra por los Tudor ${ }^{8}$. El juramento de fidelidad establecido por la reina Isabel era especialmente decidido en esta pugna con Roma. Una posición, algo más suavizada, pero idéntica en lo sustancial, fue la adoptada por Jacobo I y así quedaba recogida en el juramento de fidelidad que desencadenó la polémica en la que intervino Suárez por invitación del Papa Pablo V, escribiendo la Defensio fidei. La parte fundamental del juramento de fidelidad de Jacobo I consistía en el rechazo de la potestad indirecta del Papa sobre el rey. En efecto, el juramento establecía en su punto segundo que el Papa no tenía poder alguno para deponer al rey ni para dispensar a sus súbditos de su deber de obedecerle. Asimismo, el punto tercero disponía que si en alguna ocasión el rey fuera excomulgado o depuesto por el Papa y los súbditos dispensados de su obediencia, estos no prestarían oído a tal sentenciaª . Se rechazaba así la pretensión de todo género de poder papal sobre la política inglesa.

Desde la obra de John Neville Figgis, The divine rights of the Kings, sabemos que la lucha de la Corona inglesa contra la pretensión del poder pontificio sobre las monarquias de la cristiandad era una exigencia protestante que se había servido de la teoría del derecho divino de los reyes en Inglaterra, iniciada con el absolutismo vacilante de los Tudor y culminada con el absolutismo consolidado de los Estuardo. Así pues, para reivindicar la soberanía de la Corona inglesa y, sobre todo su independencia del poder papal, era necesario partir de un presupuesto capaz de neutralizar las pretensiones pontificias y tal principio no era otro que la idea de un origen divino de los reyes ${ }^{10}$. Sólo un poder supremo e incontestado del rey, investido como tal con la fuerza de lo Alto, podía contrarrestar la supremacía papal sobre los reyes.

3) La afirmación de Suárez (y de la escuela jesuítica en general) de la potestad indirecta del Papa era, pues, el punctum dolens tanto en Francia como en Inglaterra. Lo demuestra el hecho de que Suárez aluda en la Defensio fidei a la polémica entre Bonifacio VIII (y su Bulla Unam sanctam) y Felipe el

\footnotetext{
${ }^{8}$ En este contexto Hobbes había criticado en Leviathan 43 la teoría de la potestad espiritual, y a fortiori la potestad eclesiástica, tan indirecta como se quisiera, sobre los asuntos temporales. En su opinión, "gobierno temporal y espiritual no son sino dos palabras traídas al mundo para hacer que los hombres vean doble y confundan a su soberano legítimo", puesto que "en esta vida no hay más gobierno ni del Estado ni de la religión que el temporal" (Th. Hobbes, Leviathan, en The English works of Thomas Hobbes of Malmesbury, vol. III, John Bohn, London 1839, cap. 39, p. 460). El soberano, pues, es un único poder con competencia en ambos órdenes.

9 Suárez, F., Defensio fidei, op. cit., VI, proemium

${ }^{10}$ Cf. Neville Figgis, J., The divine rights of the Kings, 2a ed., Cambridge, Cambridge University Press, 1914, pp. 89-90.
} 
Hermoso de Francia, el conflicto con el que explota por así decir la primera reivindicación de un rey frente a la tesis de la soberanía política papal y que esta misma cuestión aparezca de nuevo en la réplica de Suárez a la condena del Parlamento francés. En realidad, los teólogos católicos del momento, pero de un modo especialmente decidido los jesuitas, sostenían todavía tal potestad indirecta. De la lista de autores repudiados por el Parlamento francés, a excepción del agustino Coqueau, todos son jesuitas (en concreto, Belarmino, Becano, Lessio, Vázquez, Azor). Ahora, sin embargo, podemos decir que aquellos teólogos estaban en un error cuando consideraban que la potestad indirecta del Papa era un dogma de fe que "había de ser sostenido y creído", como leemos en el número primero de la réplica de Suárez. En realidad, se trataba de una opinión teológica (de hecho, ya anticuada en el siglo XVII), y más en concreto, de una reliquia del agustinismo político que iría perdiendo credibilidad y vigencia entre los propios teólogos católicos con el paso del tiempo.

4) Sin embargo, creemos acertada la objeción de Suárez al Parlamento francés de que la mención del tiranicidio traída a colación por el decreto de condena del Parlamento era una simple excusa para, aprovechando el clima excitación de una época en la que dos reyes franceses habían sido lamentablemente asesinados, reafirmar la soberanía indivisa del rey francés en su territorio y añadir nuevos motivos al rechazo de la tesis de la potestad indirecta del Papa. Que, en general, entre potestad indirecta del Papa (que puede llegar a la excomunión y deposición del rey hereje o tirano) y resistencia (incluido el tiranicidio) puede haber relación es algo obvio. El propio Scorraille, historiador jesuita del pensamiento de Suárez, no esconde la posible relación entre poder temporal indirecto del Papa y deposición del rey: "Hasta dónde se extiende este poder indirecto es una cuestión que trae consigo el formidable problema del derecho de deposición de los reyes y, por consiguiente, el del derecho de resistencia de los súbditos, el del regicidio y tiranicidio" ${ }^{11}$. En tal sentido, la excomunión en 1513 de los reyes de Navarra (junto con la dispensa de obediencia para sus súbditos), decretada por Julio II, era el caso más reciente ${ }^{12}$.

\footnotetext{
${ }_{11}$ Scorraille, R. de, El P. Francisco Suárez de la Compañía de Jesús, op. cit., pp. 173-174

12 En efecto, tras la creación en 1511 de una Liga entre Fernando II el Católico, la Santa Sede, Venecia, Inglaterra y el emperador alemán Maximiliano, el Papa Julio II declaró la guerra a los franceses y por medio de la Bulla Exigit contumacium, de 18 de julio de 1513, excomulgó a los reyes de Navarra y liberó a sus súbditos del juramento de fidelidad y de la obediencia a los mismos. Esta Bula seguía a la Bula Pastor ille, de julio de 1512, del mismo Julio II en la que se excomulgaba a los aliados del rey francés. El Papa León X confirmó posteriormente la Exigit contumacium de Julio II. Estas medidas pontificas allanaban y convalidaban la anexión de Navarra a Castilla.
} 
Pero en particular, por lo que se refiere al tratamiento que Suárez da en la Defensio fidei al tiranicidio, no cabe duda de que dicha cuestión era estudiada del modo más cauto y circunspecto posible, refiriéndose como legítima únicamente a la occisión del tyrannus ab origine (es decir, el usurpador) y solo después de cumplir una larga serie de requisitos, dejando por otro lado como única causa de legítima occisión del tyrannus a regimine (el rey auténtico, aunque devenido tirano) la legítima defensa del súbdito injusta y gravemente atacado por el rey.

5) Finalmente, la censura teológica de Belarmino de la condena parisiense de la Defensio fidei tiene en realidad un punto central, sentado en el número segundo y tangencialmente en el sexto: la defensa del principio teológico-canónico de la potestad indirecta del Papa in temporalibus. Los puntos restantes no son sino la defensa del honor y buen nombre del compañero jesuita Suárez, a quien Belarmino cree injustamente atacado por el decreto del Parlamento de París. 


\section{Notas en los textos}

${ }^{1}$ El texto latino que reproducimos en la primera columna lo hemos tomado de Suárez, F., Conselhos e pareceres, tomo II, vol. II, op. cit., pp. 217-221. También se puede consultar en Pereńa, L. et alii (eds.), op. cit., pp. 597602. El documento original que reproducimos aquí es el MS. 243, fol. 352 de la Collecção Pombalina, presente en la Biblioteca Nacional de Lisboa. La Colleçáo Pombalina conserva dicho documento bajo la siguiente leyenda: "Livro do P. Francisco Soares, condemnado em França".

${ }^{2}$ El texto de la versión española de la réplica de Suárez al Parlamento de París se puede encontrar en Pereña, L. et alii (eds.), op. cit., pp. 592-596. El manuscrito original se encuentra en la Biblioteca Nacional de Lisboa, Colleçao Pombalina, MS. 243, fol. 351. El documento se puede consultar también en el Fondo Bibliográfico Antiguo de la Universidad de Granada: http://hdl.handle.net/10481/17289.

3 Como se ha dicho antes, Suárez habla de sí mismo en tercera persona.

${ }^{4}$ El sujeto de este presentan (ponunt) parece ser el conjunto de autores, con Louis Servin a la cabeza, como Fiscal general de Francia por entonces, que recopilaron la información inculpatoria contra Suárez e iniciaron y condujeron el proceso antes de ser avocado al Parlamento, donde la acusación, aunque suavizada, es acogida y refrendada en la sentencia propia.

5 Cf. Suárez, F., Defensio fidei adversus anglicanae sectae errores, en R. P. Francisci Suarez e Societate Jesu opera omnia, vol. XXIV, Parisiis, apud L. Vivès, 1859, VI, 6, 28: "Omnes Catholici doctores admittunt in Papa jurisdictionem ad regem hæreticum deponendum". Asimismo, en el mismo n. 28, algo más adelante: "Necesse est ut sit potestas in terra, quæ possit regem hæreticum pertinacem et incorrigibilem deponere. Ergo maxime esse debet in Pontifice tanquam in supremo animarum pastore visibili in terris".

${ }^{6}$ Cf. supra, nota 4

7 Suárez se refiere a la bula Unam sanctam, de 1302, de Bonifacio VIII. Cf. Suárez, F., Defensio fidei, op. cit., III, 22, 18: "Atque hac ratione dixit Bonifacius Papa, in Extrav. Unam Sanctam [...] tacite approbans sententiam Bernardi $[. .$.$] in sede Petri non solum esse spiritualem gladium, sed etiam temporalem".$

${ }^{8}$ El autor referido con el nombre de Roger es Roger Widdrington, pseudónimo, en realidad, de Thomas Preston, monje benedictino inglés, católico por tanto, y discípulo en Roma de los jesuitas, en particular de Gabriel Vázquez, pero defensor del juramento de fidelidad exigido por Jacobo I a sus súbditos y visto con simpatía en Francia. La obra de Widdrington a la que aquí se refiere Suárez es Disputatio theologica de Iuramento fidelitatis Sanctissimo Patri Paulo Pape Quinto dedicata, Albionopoli [Londres], ex oficina Theophili Fabri, permissu superiorum, 1613.

9 Cf. Suárez, F., Defensio fidei, op. cit., III, 23. En esta cita Suárez reitera el título del capítulo 23 del libro III: "Pontificem Summum potestate coerciva in reges uti posse, usque ad depositionem etiam a Regno, si causa subsistat".

10 Se refiere Suárez con estas palabras a la declaración del Parlamento de París, de 20 de junio de 1614 en cuya versión traducida se dice: "Se notará que Suárez, habiendo alegado muchos exemplos de deposiciones de muchos reyes de diversos Reynos, no ha hablado de ninguna de Espańa en que ha mostrado exceptuarlos y librarlos de la pretendida jurisdicción pontificia a la qual somete a los otros". La expresión en cursiva está anotada por el propio Suárez en nota marginal con la expresión: "Ojo, calumnia”. Cf. "Declaración de Parlamento y asiento de las pruebas del Fiscal en el Parlamento (30 de junio de 1614)”, en Pereńa, L. et alii (eds.), op. cit., p. 584.

11 Es decir, Louis Servin. Cf. supra, nota 4

12 El teólogo católico aquí aludido es el jesuita Leonardo Lessio (1554-1623), autor de una epístola titulada Exemplum litterarum cuiusdam theologi en la que se ataca como contraria a la fe católica la doctrina de la obra de Roger Widdrington, Apologia pro iure principum, Cosmopoli, apud Theophilum Pratum, 1611. A la carta de este cierto teólogo (cuiusdam theologi, Lessio como sabemos) se refiere el documento titulado "Declaración del 
Parlamento y asiento de las pruebas del Fiscal en el Parlamento de París, de 20 de junio de 1614 ” y recogido por Pereńa, L. et alii (eds.), op. cit., p. 586.

${ }^{13}$ Ad ocultandam, para disimular o para ocultar.

${ }_{14}$ El tratamiento del tiranicido en la Defensio fidei se aborda en el libro VI, 4, especialmente en los puntos 2 (Princeps licet tyrannice gubernet non potest licite privata auctoritate interfici), 5 (Liceatne in defensionem propriae vitae principem occidere), 6 (Quid in reipublica defensionem) y 7 (Tyrannus in titulo licite occiditur).

${ }_{15}$ Corregimos un error de sintaxis latina, dado que el adjetivo pontificia no concuerda en caso con su sustantivo auctoritatem, en acusativo.

16 Se refiere Suárez aquí a las elogiosas censuras teológicas que constan al inicio de la Defensio fidei, realizadas por los obispos de Coimbra, Algarve y Lamego. El cuarto obispo referido es don Pedro del Castillo, virrey de Portugal e Inquisidor supremo de Portugal.

17 Nota marginal del propio Suárez: "Ex Anastasio in Hormisda, et Hincmaro in vita Remigij apud Surium, tom. I. die 13. Januarij, et concordat Baronius tom. 6. anno 514. n. 14”.

${ }^{18}$ Del contexto se deduce que estos herejes son los protestantes. Suárez es un autor de la Contrarreforma. Estos Acta et decreta han sido escritos solamente a cincuenta ańos de distancia del concilio de Trento (1545-1563), cuya convocatoria se debió precisamente a las diferencias doctrinales con los reformadores.

19 Papa Hormisdas (450-523)

${ }^{20}$ Roberto Belarmino (1542-1621), teólogo y cardenal jesuita, seguramente el autor con más prestigio dentro de la Compañía de Jesús a finales del siglo XVI e inicios del siglo XVII.

${ }^{21}$ Martín Becan (1563-1624), teólogo jesuita, profesor de teología en Alemania y Austria, apellidado en realidad Schellekens, pero conocido como Becan en consideración de su ciudad natal, Hilvarenbeek, en Flandes, cerca de Amberes. En efecto, el nombre de Becan (Becanus) es la latinización de la partícula final beek de Hilvarenbeek.

22 Leonardo Lessio (1554-1623), teólogo moral jesuita, profesor en la Universidad de Lovaina. Cf. supra, nota 12.

${ }^{23}$ Leonardo Coquaeu, eremita agustino (†1615), autor del Examen Praefationis monitoriae Iacobi I. Magnae Britanniae et Hiberniae Regis, Friburgi Brigoiae, apud Joannem Strasserum, 1610.

24 Gabriel Vázquez (1549-1604), filósofo y teólogo jesuita, profesor en Alcalá de Henares y Roma.

25 Juan Azor (1536-1603), teólogo jesuita dedicado al estudio de cuestiones morales, considerado uno de los padres de la casuística moderna.

${ }^{26}$ Se trata de una cita de Defensio fidei, III, 11, 5, donde Suárez se refiere directamente a la potestad del Papa en asuntos espirituales o eclesiásticos, pero dejando abierta la posibilidad de que dicha potestad se extienda también, aunque sea indirectamente, a los asuntos temporales o civiles. Dice, en efecto, este texto: "Bellarminus ergo, et nos omnes qui in hac causa unum sumus, ex illis locis non probamus proxime et immediate primatum Petri in civilibus seu temporalibus, sed in ecclesiasticis seu spiritualibus; an vero hæc potestas spiritualis ad temporalia extendatur, alia quæstio est tractanda et decidenda".

27 Henri de Sponde (1568-1645), nacido calvinista y posteriormente convertido al catolicismo, llegó a ser obispo de Pamiers en 1626. Es el autor de los Annalium Cardinalis Baronii continuatio, que completa la obra de Baronio (quien deja incompleta su historia de la Iglesia a la altura del siglo XII), escribiendo hasta la fecha de 1640. 
${ }^{28}$ César Baronio (1538-1607), sacerdote del Oratorio de san Felipe Neri y posteriormente cardenal, fue un influyente historiador de la Iglesia. Su obra principal son los Annales ecclesiastici en doce volúmenes (1508-1607), una historia de la Iglesia hasta el siglo XII, escrita con el propósito de responder a la obra luterana Historia Ecclesiae Christi, escrita por un grupo de teólogos e historiadores luteranos de Magdeburgo.

29 Anastasio Bibliotecario (810-879) fue un monje romano y uno de los autores del Liber pontificalis, una compilación biográfica de los primeros Papas hasta Esteban V (891). En la sección del Papa Hormisdas, el Liber Pontificalis afirma de un modo oscuro: "Eodem tempore uenit regnus cum gemmis praetiosis a rege Francorum Cloduueum christianum, donum beato Petro apostolo", que podemos traducir: "Por el mismo tiempo el reino vino [fue entregado] con gemas preciosas por Clodoveo, el rey cristiano de los francos, como don al beato apóstol Pedro) (LIV, 10). También en Anastasii, S.R.E. Bibliothecarii Historia de vitiis romanorum pontificum a B. Petro Apostolo usque ad Nicolaum I, Moguntiae, in typographeio Joanni Albini, 1602, p. 48, donde se corrigen algunos defectos sintácticos y se dice: "Eodem tempore venit regnum cum gemmis pretiosis a Rege Francorum Clodoueo Christiano donum Beato Petro Apostolo [...]”.

${ }^{30}$ La obra referida por Belarmino es Nicole Gilles, Annales et croniques de France, François Regnault, Paris 1551.

31 El rey inglés mencionado es Jacobo I. El Prefacio monitorio, a su vez, es un añadido a la segunda edición de su obra la Apologia pro iuramento fidelitatis, publicada en 1609.

32 Paulus Emilius Veronensis (1455-1529), historiador y cronista de origen italiano, autor de De rebus gestis Francorum libri X, Parisiis, in aedibus Iodoci Badii Ascensii, 1517.

33 A la llamada Carta declaratoria (en concreto, Lettre declaratoire de la doctrine des Peres jesuites conforme aux Décrets du Concile de Constance, adressée à la Royne, Mère du Roy, regente en France, Lyon 1610) del jesuita francés Pierre Coton, un autor anónimo respondió en 1610 con un Anti-Coton (Anticoton, ou Refutation de la Lettre Déclaratoire du Père Coton, livre où est provvè que les Jesuites sont coulpables et autheurs du parricide execrable commis en la personne du Roy tres-Chretien Henry IV, d'heureuse mémoire, 1610) cuyo primer capítulo llevaba por título Que la doctrine des Jesuits approvve le parricide des Rois et la rebellion des sujets.

34 Se trata de la residencia de los jesuitas de París, donde habitaban los padres jesuitas llamados al proceso contra la Defensio fidei. 


\section{REFERENCIAS Bibliográficas}

Anastasio Bibliotecario, Historia de vitiis romanorum pontificum a B. Petro Apostolo usque ad Nicolaum I, Moguntiae, in typographeio Joanni Albini, 1602

anónimo, Anticoton, ou Refutation de la Lettre Déclaratoire du Père Coton, livre où est provvè que les Jesuites sont coulpables et autheurs du parricide execrable commis en la personne du Roy tres-Chretien Henry IV, d'heureuse mémoire, 1610

Baronio, C., Annales ecclesiastici, 12 vols., Antverpiae, Ex officina Plantiniana

Carvalho, J. De, "Nota preliminar" de Suárez, F., Conselhos e pareceres, tomo I, Acta Universitatis Conimbrigensis, Coimbra, Atlántida, 1948

Coquaeu, L., Examen Praefationis monitoriae Iacobi I. Magnae Britanniae et Hiberniae Regis, Friburgi Brigoiae, apud Joannem Strasserum, 1610

Cotтon, P., Lettre declaratoire de la doctrine des Peres jesuites conforme aux Décrets du Concile de Constance, adressée à la Royne, Mère du Roy, regente en France, Lyon 1610

Hоввеs, TH., Leviathan, en The English works of Thomas Hobbes of Malmesbury, vol. III, John Bohn, London 1839

Pereña, L. et aliI (eds.), Francisco Suárez, De iuramento fidelitatis. Estudio preliminar. Conciencia y politica, Madrid, CSIC, 1979

Neville Figgis, J., The divine rights of the Kings, 2a ed., Cambridge, Cambridge University Press, 1914

Paulus Emilius Veronensis, De rebus gestis Francorum libri X, Parisiis, in aedibus Iodoci Badii Ascensii, 1517

Scorraille, R. de, El P. Francisco Suárez de la Compañia de Jesús, Pamplona, Analecta, 2 vols., 2005

Sponde, H. De, Annalium Ecclesiasticorum Eminentiss Cardinalis Caesaris Baronii Continuatio, 2 vols., Lutetiae Pasisiorum, Impensis Societatis Typographicae Librorum officij Ecclesiastici, 1647-1659

SuÁrez, F., "Indicios y pruebas de las actas y decretos del Parlamento de París contra el libro de sobre la defensa de la fe de Francisco Suárez", en Fondo Bibliográfico Antiguo de la Universidad de Granada, https://digibug.ugr.es/handle/10481/17289 
SuÁrez, F., Conselhos e pareceres, 3 vols., Acta Universitatis Conimbrigensis, Atlántida, Coimbra 1948-1952

SuÁrez, F., Defensio fidei adversus anglicanae sectae errores, en R. P. Francisci Suarez e Societate Jesu opera omnia, vol. XXIV, Parisiis, apud L. Vivès, 1859

SuÁrez, F., Tractatus de Gratia Dei seu de Deo Salvatore, justificatore et liberi arbitrii adjutore per gratiam suam, en R. P. Francisci Suarez e Societate Jesu opera omnia, vol. VII, Parisiis, apud L. Vivès, 1857

Widdrington, R. (Preston, Th.), Apologia pro iure principum, Cosmopoli, apud Theophilum Pratum, 1611

Widdrington, R. (Preston, Th.), Disputatio theologica de Iuramento fidelitatis Sanctissimo Patri Paulo Pape Quinto dedicata, in qua potissima omnia argumenta, que a Card. Bellarmino, Iacobo Gretzero, Leonardo Lessio, Martino Becano, alijs$q$ [ue] nonnullis contra recens Fidelitatis iuramentum ex decreto Regii \& Parliamenti, in Anglia stabilitum hactenus facta sunt, syncere, dilucide, et accurate examinantur, Albionopoli [Londres], ex oficina Theophili Fabri, 1613

DOI: https://doi.org/10.15366/bp.2020.24.006

Bajo Palabra. II Época. No 24. Pgs: 107-134 
